\title{
Editorial: recent advances in the knowledge of cephalopod biodiversity
}

\author{
Michael Vecchione ${ }^{1} \cdot$ Elaina M. Jorgensen $^{2} \cdot$ Yasunori Sakurai $^{3}$
}

Received: 5 July 2017 / Accepted: 13 July 2017 / Published online: 27 July 2017

(C) US Government (outside the USA) 2017

Despite a relatively low level of species diversity, living cephalopods are quite diverse in other ways. For example, the morphological variability among the many families of oegopsid squids, and in some cases within families, is very high and can be confusing because of convergent evolution. Developmental allometry and other morphological changes with ontogeny, while not technically metamorphosis, can be extreme and developmental stages have often been described as new taxa. Even at the individual level, dynamic changes in the shape and skin patterns of many coastal species are the fastest and most extreme known, adding a dazzling amount of morphological diversity. Other aspects of cephalopod behavior are diverse as well. These characteristics all confound our ability to identify cephalopods and, therefore, our knowledge of what lives where. Recent advances in molecular analyses and other technologies, such as imaging, have facilitated advances toward resolving some of these issues. It is important to remember, though, that continued and consistent use of traditional methods also contribute to the accumulation of knowledge, especially in areas (both geographic and disciplinary) where studies have been limited and when new analytical methods are applied.

Communicated by Sabine Gollner

Michael Vecchione

vecchiom@si.edu

1 NMFS National Systematics Laboratory, National Museum of Natural History, Washington, DC 20013-7012, USA

2 NOAA National Marine Fisheries Service, 7600 Sand Point Way NE, Seattle, WA 98115, USA

3 Hakodate Cephalopod Research Center, Fisheries and Oceans Hakodate, Benten-cho 20-5, Hakodate, Hokkaido 040-0051, Japan
This special issue is a compilation of contributions considering many of these aspects of cephalopod diversity. Most of the papers were originally presented at the 2015 meetings sponsored by the Cephalopod International Advisory Council in Hakodate, Japan.

Family-level systematics have been fairly stable for extant cephalopods other than several changes in level (e.g., to or from super- or subfamily) and the addition of a few recently discovered families. However, relationships among families have been controversial. Braid et al. (2017) contribute to resolution of this problem using phylogenetic methods for analyses of DNA sequences to examine evolutionary relationships among and within a diverse group of oegopsid families that had been defined based on their strange morphology.

The cephalopod fauna remains poorly known in many areas of the ocean. Three of these papers assess the taxonomic diversity of oceanic cephalopods in distinct but adjacent geographic areas. Lischka et al. (2017) discussed distributional relationships of midwater species collected by trawling down to depths of $300 \mathrm{~m}$ or $1000 \mathrm{~m}$, depending on the size of the net, on a cruise across the subtropical convergence zone of the Sargasso Sea (western North Atlantic). Farther west, in the Gulf of Mexico, Judkins et al. (2017) compared the diversity of midwater cephalopods inferred by using two very different types of midwater trawls, one type a very large net and the other a smaller gear rigged with multiple nets so that separate discrete samples can be collected in a single deployment. Also in the North Atlantic but farther north and closer to the North American continental slope, Shea et al. (2017) reported the results of a multi-year study using similar very large nets but, in this case, including both midwater and bottom sampling.

Simply identifying cephalopod species can be quite challenging. The lack of hard parts and paucity of fixed meristic characters frequently frustrate taxonomic efforts. Another set 
of these papers deals with species-level identification and the implications of mis-identification. Lima et al. (2017) determined the distribution of a species of Octopus that was recently distinguished from the global "catch-all" species, $O$. vulgaris sensu lato, and established that mis-identification has occurred regionally in the management of commercial harvesting. A similar problem was examined for the coastal squid Doryteuthis sanpaulensis by Braga et al. (2017) using geometric morphometrics. Many deep-sea species are very poorly known, and Braid (2017) critically examined one such species, Asperoteuthis lui, using combined morphological and molecular methods to resolve its status and determine its distribution. Sukhsangchan et al. (2017) reared eggs of multiple species of cephalopods from Thai waters to hatching so that the paralarvae could be confidently identified during subsequent studies. Also in Thai waters, Tuanapaya and Nabhitabhata (2017) examined a large number of morphological characters from a large sample of a morphologically variable cuttlefish species, Sepia pharaonis, and determined quantitatively that four morphological groups corresponded with four general color patterns that have been distinguished geographically in local waters.

Nakajima and Ikeda (2017) used a different approach to understanding the variability of $S$. pharaonis; they carefully recorded and enumerated the morphological patterns exhibited by individual cuttlefishes from Okinawa Island, Japan. Finally, a short note (Vijai et al. 2017) reports on unusual behavior within a school of squid.

Recent work has highlighted cephalopods as a unique group among invertebrates for neural complexity and genome size and, more broadly unusual among animals, for genomic function. We hope that, in addition to the conclusions of the individual contributions, the papers in this special issue will further the general understanding of patterns of diversity in these fascinating animals.

\section{References}

Braga R, Crespi-Abril AC, Van der Molen S, Bainy MCRS, Ortiz N (2017) Analysis of the morphological variation of Doryteuthis sanpaulensis (Cephalopoda: Loliginidae) in Argentinian and Brazilian coastal waters using geometric morphometrics techniques. Mar Biodivers (this issue). doi:10.1007/s12526-017-0661-z

Braid HE (2017) Resolving the taxonomic status of Asperoteuthis lui Salcedo-Vargas, 1999 (Cephalopoda, Chiroteuthidae) using integrative taxonomy. Mar Biodivers (this issue). doi:10.1007/s12526-0160547-5

Braid HE, Kubodera T, Bolstad KSR (2017) One step closer to understanding the chiroteuthid families in the Pacific Ocean. Mar Biodivers (this issue). doi:10.1007/s12526-016-0628-5

Judkins H, Vecchione M, Cook A, Sutton T (2017) Diversity of midwater cephalopods in the northern Gulf of Mexico: comparison of two collecting methods. Mar Biodivers (this issue). doi:10.1007/ s12526-016-0597-8

Lima FD, Berbel-Filho WM, Leite TS, Rosas C, Lima SMQ (2017) Occurrence of Octopus insularis Leite and Haimovici, 2008 in the tropical northwestern Atlantic and implications of species misidentification to octopus fisheries management. Mar Biodivers (this issue). doi:10.1007/s12526-017-0638-y

Lischka A, Piatkowski U, Hanel R (2017) Cephalopods of the Sargasso Sea: distribution patterns in relation to oceanography. Mar Biodivers (this issue). doi:10.1007/s12526-016-0629-4

Nakajima R, Ikeda Y (2017) A catalog of the chromatic, postural, and locomotor behaviors of the pharaoh cuttlefish (Sepia pharaonis) from Okinawa Island, Japan. Mar Biodivers (this issue). doi:10. 1007/s12526-017-0649-8

Shea EK, Judkins H, Staudinger MD, Dimkovikj VH, Lindgren A, Vecchione M (2017) Cephalopod biodiversity in the vicinity of bear seamount, western North Atlantic based on exploratory trawling from 2000 to 2014. Mar Biodivers (this issue). doi:10.1007/ s12526-017-0633-3

Sukhsangchan C, Sunthornket P, Phuynoi S (2017) Morphological characteristics of paralarvae of cephalopods found in Thai waters. Mar Biodivers (this issue). doi:10.1007/s12526-016-0588-9

Tuanapaya S, Nabhitabhata J (2017) Morphometry and morphological phylogeny of Sepia pharaonis Ehrenberg, 1831 complex in Thai waters. Mar Biodivers (this issue). doi:10.1007/s12526-017-0682-7

Vijai D, Puneeta P, Matsui H, Morooka M, Sakurai Y (2017) Intraspecific kleptoparasitism in squid school and schooling behavior of its prey. Mar Biodivers (this issue). doi:10.1007/s12526-016-0549-3 